\title{
Numerical Characterization of Behavior Under Uniaxial Tension and Modelling of Bending of Mechanical Behavior of Polymeric Materials (HIPS) And Comparison with Experience
}

\author{
Meryem Baha ${ }^{1 *}$, Amal Lamarti ${ }^{2}$, Rachid Sehaqui ${ }^{1}$, Abdelilah Hachim $^{3}$, Siham Ouhimmou ${ }^{1}$ \\ ${ }^{1}$ Faculty of Science Ain-Chock. Hassan II University, Km 8 Route d'El Jadida, Laboratory of \\ Mechanics, Casablanca, Morocco. \\ ${ }^{2}$ National higher school of mechanics, ENSEM, Laboratory of Control and Mechanical \\ Characterization of Materials and Structures, Casablanca, 20232, Morocco. \\ ${ }^{3}$ Institute of Maritime Studies, ISEM, Laboratory of Control and Mechanical Characterization of \\ Materials and Structures, ENSEM, Casablanca, 20232, Morocco
}

\begin{abstract}
Considering the wide use of high impact polystyrene in different fields, it is important to know its behavior in different environmental conditions. This work is interested in the characterization of the behavior of high impact polystyrene (HIPS) under tensile and bending stress.
\end{abstract}

\section{Introduction}

High Impact Polystyrene (HIPS) is a thermoplastic material used in low temperature applications, it is characterized by the addition of plasticizer or rubber to the base polystyrene. Due to the increasing use of this polymer, it seems necessary to study its behavior in order to be able to use it under the best conditions.

During this work, based on a numerical simulation software, we will do a numerical modeling of the behavior of high impact polystyrene during tensile and three-point bending tests.

\section{Properties of material}

Tensile (figure 3) and bending (figure 4) tests were modeled in simulation software, for an imposed displacement.

The characteristics of high impact polystyrene are [1]:

- Young's modulus: $\mathrm{E}=240 \mathrm{MPa}$

- Poisson's ratio: $v=0.35$

The dimensions of the sample are shown in Figure 1.

\footnotetext{
* Corresponding author: baha.meryem1@gmail.com
} 


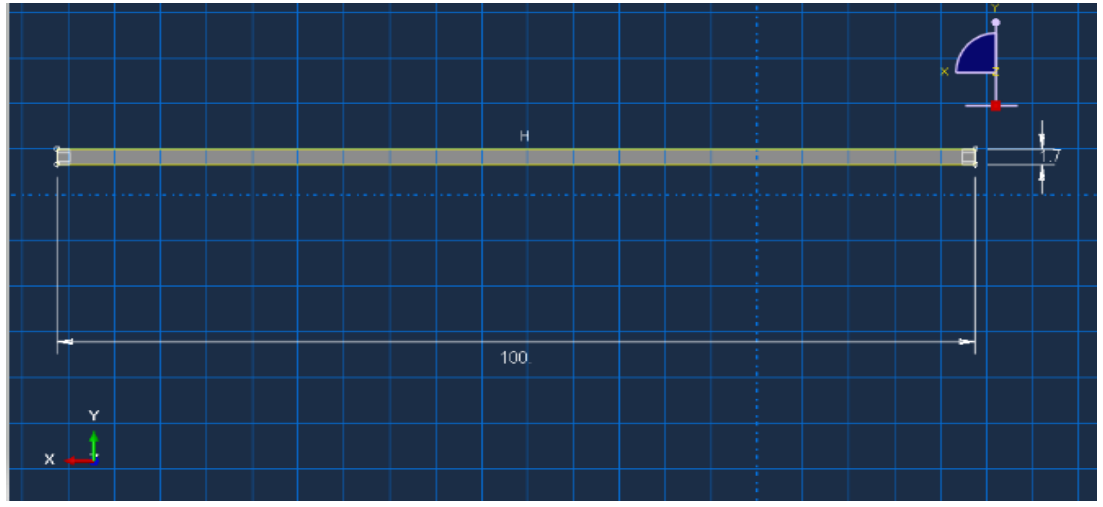

Fig. 1. Dimension of the specimen.

To carry out this numerical study, we chose a mesh of 1 , type C3D8R, presented in figure 2.

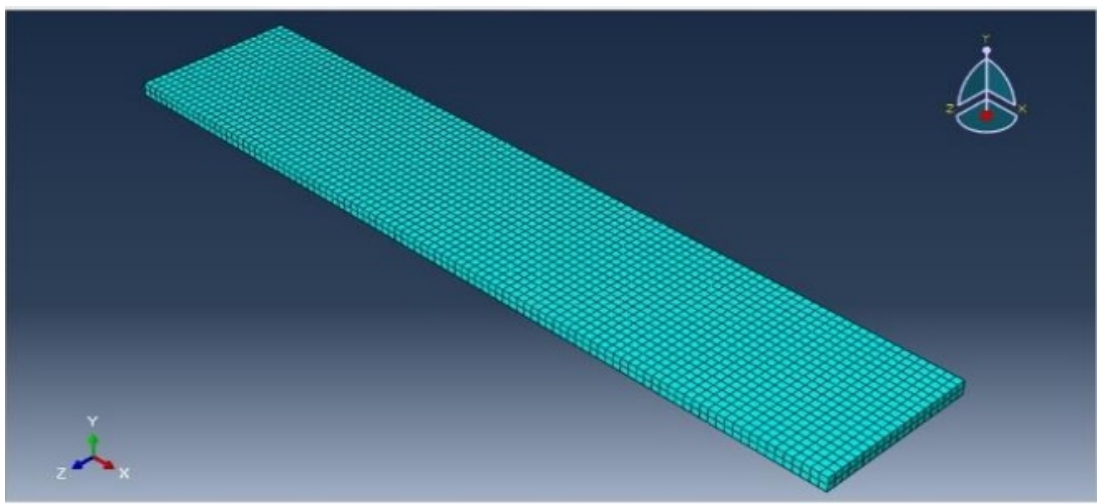

Fig. 2. Mesh of the specimen

The digital model of the tensile test is shown in the following figure:

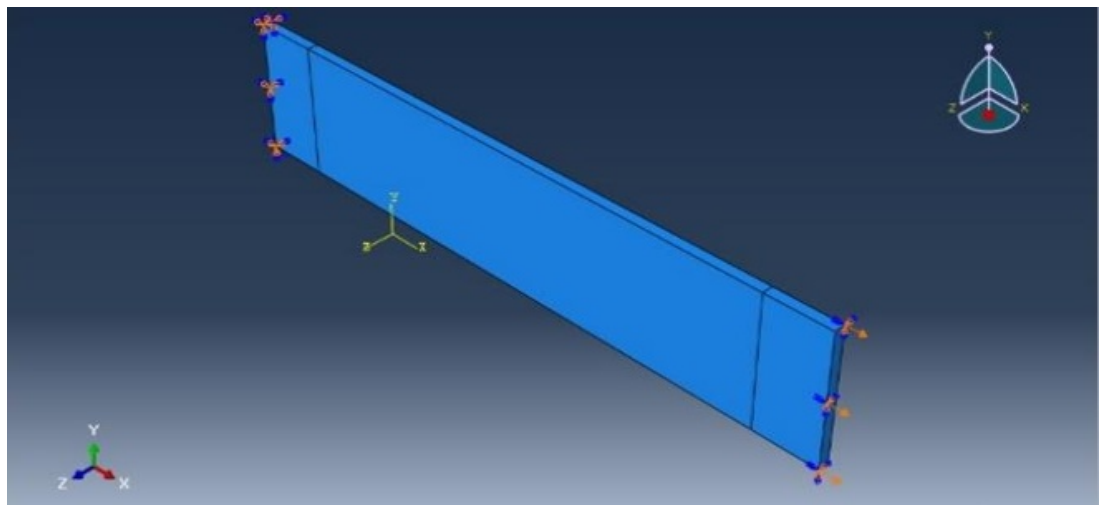

Fig. 3. Tensile test model 
Figure 4 illustrates the three-point bending test model.

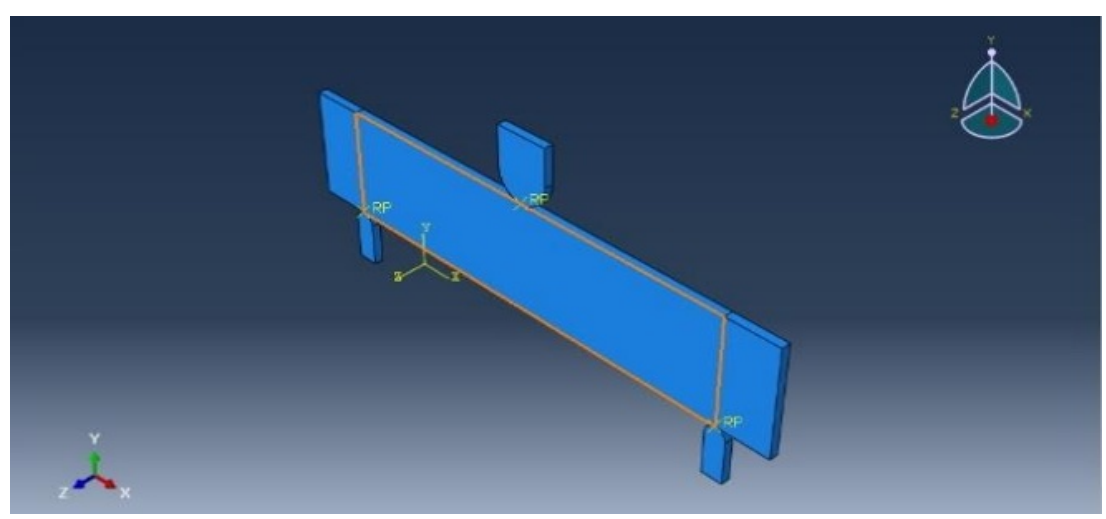

Fig. 4. Three-point bending test model

\section{Results}

The following figures represent the stress-strain curves of high impact polystyrene, obtained from a numerical simulation by commercial software.

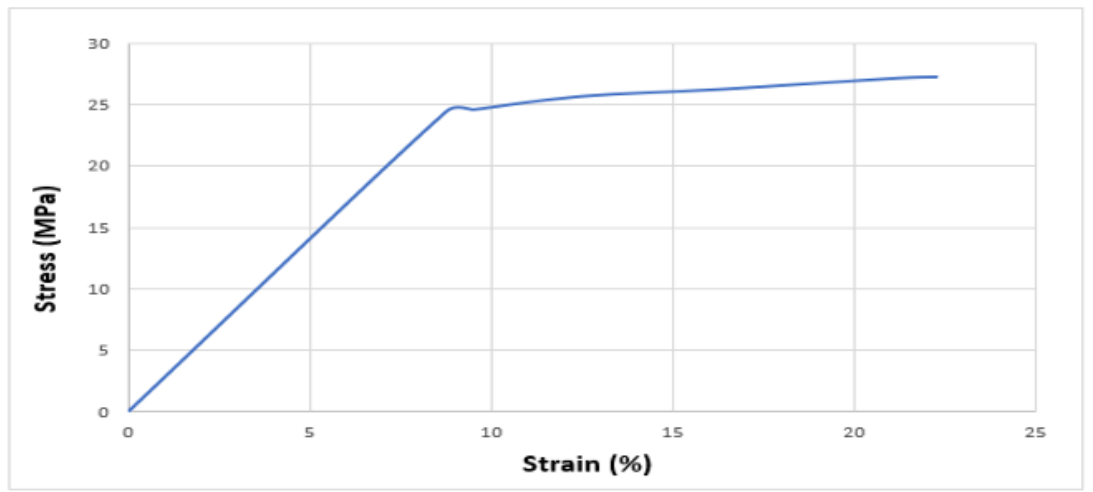

Fig. 5. Numerical stress-strain curves of high impact polystyrene during tensile test.

According to Figure 5, we can notice that there are two areas in the curve, the first one called linear area in which the material behaves elastically and Hooke's law is respected (24MPa). And a nonlinear area characterized by a rapid decrease in stress followed by an increase to a stress value equal to $28 \mathrm{MPa}$ for higher strains. 


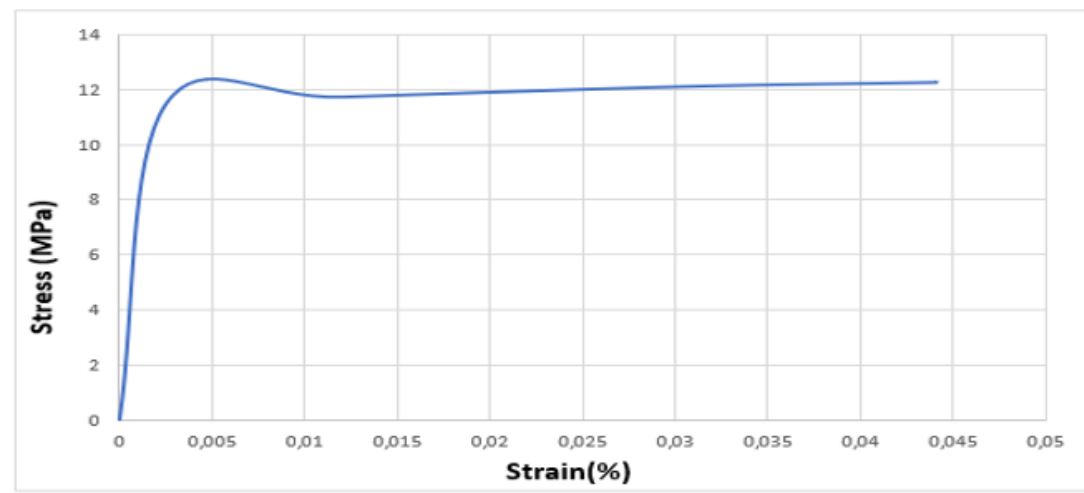

Fig. 6. Numerical stress-strain curves of three-point bending test (high impact polystyrene).

In the case of a three-point bending test (figure 6), the curve shows a linear increase in stress (elastic regime), followed by a drop in stress from $12.2 \mathrm{MPa}$ to $11.4 \mathrm{MPa}$, and a slow increase to $12.3 \mathrm{MPa}$. The deformations in this plastic regime are irreversible.

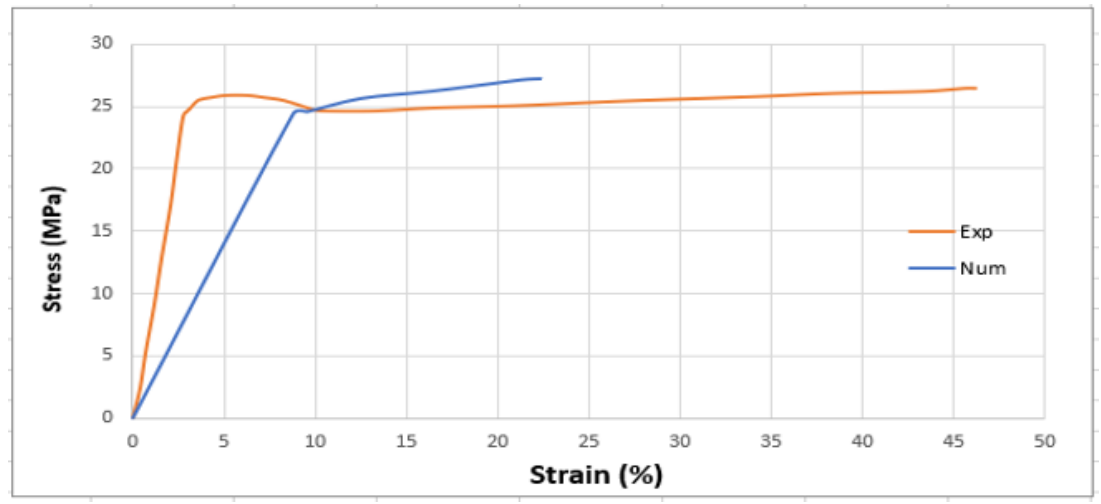

Fig. 7. Experimental [3] and numerical stress-strain curves of high impact polystyrene during tensile test.

Figure 7 represents the numerical and experimental stress-strain curve. By comparing the two stress-strain curves, we notice that in both cases the elastic limit is about $25 \mathrm{MPa}$.

\section{Conclusions}

In this work, we performed a numerical simulation of polystyrene (HIPS) during tensile and three points bending tests, for un-notched specimens, using commercial simulation software. Then we described the evolution of the stress-strain curve in the two stress cases. And compare the tensile curve to the experimental one.

\section{References}


1. H. El Bhilat, A. Hachim, K. El Had, Jcarme. The. Mec. Cha. Of Post-Cons Rec. Hips: Inf. of the Nbr. Of Pro. Cy., 10 (2018)

2. J. Lecomte-Beckers. Physique Des Matériaux : Partie Polymères.

3. H. El Bhilat, K. Elhad, H. Salmi, A. Hachim, 2019. Un Modèle D'endommagement Statique Thermomécanique Base Sur L'altération des Caractéristiques Mécaniques Du Polystyrène-Choc (Hips), In Proceeding of the 14e Congress of Mechanics, Rabat, (2019) 